\title{
O paradoxo da abundância: recursos naturais e desenvolvimento na América Latina
}

\author{
JOÃO BATISTA PAMPLONA ${ }^{I}$ \\ - MARIA CRISTINA CACCIAMALI II
}

\section{Introdução}

A

TEMÁTICA do desenvolvimento reemerge na América Latina, e entre seus novos contornos está o desafio de repensar as implicações das estruturas produtivas centradas em recursos naturais no desenvolvimento econômico dos países da região. Constitui-se assim o objetivo deste artigo, que é identificar e interpretar as potencialidades e riscos da maior concentração da estrutura produtiva em recursos naturais e em produtos intensivos nesses recursos, e como tais potencialidades e riscos condicionam as estratégias de desenvolvimento econômico para a América Latina. Para atingir esse objetivo e compreender de forma mais ampla o papel das atividades econômicas centradas em recursos naturais no desenvolvimento econômico da América Latina, o enfoque que adotamos pressupõe o desenvolvimento econômico como processo contínuo e não automático de mudança estrutural, condicionado pela história e por escolhas de agentes sociais e políticos em conflito, baseado em acumulação de capital, inovação tecnológica e evolução institucional, para o qual o papel ativo do Estado é fundamental.

O início do século XXI trouxe uma importante mudança de contexto histórico para os países da América Latina. Há uma nova realidade global, caracterizada pelo fenômeno chinês, pela ampla difusão das Tecnologias de Informação e Comunicação (TIC) e pela globalização dos mercados e cadeias produtivas.

A China ganhou centralidade no mercado global, como primeiro exportador e segundo importador do mundo - fala-se em mercado "sinocêntrico". Ela tem vantagens inequívocas em vários segmentos industriais, especialmente indústria de montagem. O ritmo de crescimento e a dimensão de sua economia fazem da China uma grande demandante de matérias-primas e outros produtos primários. O fenômeno chinês explica em boa medida a trajetória ascendente dos preços das commodities primárias na década de 2000, o que significou naquele período a reversão dos termos de intercâmbio a favor dos produtos intensivos em recursos naturais.

A presença global da China, a partir dos anos 2000, representa um redesenho da divisão internacional do trabalho. ${ }^{1}$ Os chineses estão entre os princi- 
pais parceiros comerciais de países da América do Sul. E, torna-se indispensável considerar a China em qualquer estratégia de desenvolvimento para a América Latina.

A revolução das TIC e a globalização trazem intensa segmentação dos mercados, das cadeias produtivas e das tecnologias. Os nichos de mercado se multiplicam. Os produtos customizados e diferenciados criam novas situações de quase monopólios. Essa intensa segmentação poderia estar transformando em commodities produtos manufaturados e fazendo produtos de origem primária deixarem de ser commodities. A nova complexidade do mercado global indica para alguns autores a possibilidade de pensar no desenvolvimento não mais apenas como resultado da industrialização. Segundo Pérez (2010), por exemplo, diante das condições atuais da economia global, há janelas de oportunidade a serem aproveitadas com a criação de estratégia de desenvolvimento baseada em recursos naturais para os países da América Latina. Nesse caso, o Brasil que mostra ampla e variada oferta de recursos naturais e uma estrutura industrial consolidada teria condições ainda mais favoráveis para o sucesso de uma estratégia de diversificação e dinamização tecnológica por meio da base primária?

$\mathrm{Na}$ busca por respostas, é preciso considerar a ideia de que recursos naturais não são uma simples "dotação", "dote” ou "dádiva” da natureza, mas antes uma riqueza que só se efetiva com capital, tecnologia e conhecimento. Além disso, o atual paradigma tecnoeconômico permite que novas fronteiras tecnológicas - como é o caso dos bioprodutos ou química verde - aumentem a eficiência schumpeteriana de atividade intensivas em recursos naturais. Deve-se também levar em conta que há exemplos de países que não reagiram de forma passiva e rentista aos booms de commodities, conseguindo internalizar e multiplicar os ganhos do comércio internacional por meio da criação e expansão de amplo leque de atividades econômicas nacionais. O Canadá, a Austrália, a Nova Zelândia e a Noruega são países que conseguiram atingir elevado nível de desenvolvimento com economias baseadas em recursos naturais.

Não obstante os exemplos de países bem-sucedidos em sua estratégia de desenvolvimento baseada em recursos naturais, as alterações do contexto econômico global e as possíveis ações do Estado para combater efeitos deletérios, muitos autores ainda identificam riscos em uma estratégia como essa para os países da América Latina. Alertam para a possibilidade de uma reprimarização das economias da região e para o surgimento de desindustrialização em países do sul do continente, como consequências da crescente interdependência entre China e América do Sul (Barbosa et al., 2014; Lederman; Olarreaga; Perry, 2008). Nutrido pela tese Prebish-Singer dos anos 1950 e seus desdobramentos, prevalece ainda hoje para muitos especialistas o reconhecimento de que a manufatura e os serviços intensivos em conhecimento constituiriam o verdadeiro núcleo irradiador do desenvolvimento. As atividades intensivas em recursos naturais, resultantes da abundância desses recursos, estariam associadas à baixa in- 
tensidade de inovações, à diminuta capacidade de gerar bons empregos, a saldos comerciais efêmeros que sobrevalorizam o câmbio, à concentração de renda, e até mesmo à corrupção.

O fato é que a clássica e marcante discussão sobre a contribuição da oferta elástica de recursos naturais para o desenvolvimento da América Latina prossegue, e está agora revigorada com ingredientes trazidos pelas alterações do contexto histórico, das mudanças significativas da realidade econômica global, do aprendizado com o passado, da concepção de padrões aperfeiçoados de ação institucional e do Estado para lidar com os recursos naturais. Essas mudanças e a redução do espaço da pauta macroeconômica renovam e ampliam o interesse - e também a necessidade - acerca das discussões das estratégias de desenvolvimento que assegurem aos países latino-americanos crescimento econômico de longo prazo, equidade social e elevado padrão tecnológico da estrutura produtiva.

Desse modo, a controvérsia na literatura acerca das potencialidades e riscos associados à maior concentração da estrutura produtiva e das exportações em recursos naturais e em manufaturas intensivas nesses recursos não apenas persiste, mas se torna mais complexa, rica e instigante. Isso faz necessárias a sistematização da literatura especializada e a sua análise crítica. Assim sendo, a primeira parte deste artigo desdobra-se nas seções 1 e 2, que apresentam, organizam e interpretam a literatura recente sobre a relação entre desenvolvimento econômico e abundância - ou especialização - de recursos naturais. Ao passo que a segunda parte, representada pela seção 3 , reflete acerca dos efeitos que novas oportunidades e antigos desafios da estrutura produtiva centrada em recursos naturais teriam sobre as estratégias de desenvolvimento econômico para a América Latina. Por fim, nas considerações finais, e como resultado das seções anteriores, são apontados de forma condensada alguns princípios e estratégias gerais para o desenvolvimento da América Latina.

\section{A ideia de recursos naturais como fardo para o desenvolvimento}

A abundância de recursos naturais - minerais, hidrocarbonetos, água, terras agricultáveis, florestas entre outros - dos países da América Latina tem sido interpretada mais como um risco do que como uma oportunidade por parte relevante da literatura sobre desenvolvimento econômico. Entre a "benção" e a "maldição", a análise estruturalista ou desenvolvimentista destacou a dimensão prejudicial - a "maldição" - para as economias baseadas no uso intensivo de recursos naturais (Prebisch, 1949; Ocampo; Parra-Lancourt, 2010; Vieira; Avellar; Veríssimo, 2013; Abelles; Rivas, 2010; Bresser-Pereira; Gala, 2010). Estabeleceu-se algo que podemos chamar de "paradoxo da abundância", no qual a generosidade da natureza representada pela profusão de recursos naturais - que fez que os primeiros exploradores europeus das Américas preterissem as colônias do norte e cobiçassem as colônias do sul ${ }^{2}$ - origina, entre outros efeitos deletérios, baixo crescimento econômico no longo prazo. 
A ideia de atividades intensivas em recursos naturais como duvidosas já encontrava abrigo em autores clássicos como Adam Smith. ${ }^{3}$ Mas ela só ganha relevo na literatura sobre desenvolvimento com a tese Prebisch-Singer (Prebisch, 1949; Singer, 1950), que apontava a deterioração dos termos de intercâmbio (DTI) dos países produtores de matérias-primas e outros primários no longo prazo. A consequência prática dessa tese era a necessária mudança estrutural da economia subdesenvolvida em direção ao processo de industrialização, visto como único caminho para o desenvolvimento. ${ }^{4}$

Kaldor (1978, p.125-6) enfatizou a singularidade da indústria ao afirmar que o tipo de crescimento econômico que inclui tecnologias modernas e alta renda per capita é inconcebível sem um moderno setor manufatureiro. Para ele, um país inteiramente especializado em produtos primários, e que portanto obtém seus produtos industriais de fora, nunca será um país com alta renda per capita.

A ideia da produção baseada em recursos naturais como fardo para o desenvolvimento prosseguiu. Nos anos 1970, criou-se a noção de "doença holandesa". O boom exportador de gás da Holanda no período originou sobrevalorização cambial que reduziu - crowding out - o setor manufatureiro. O rápido aumento do valor dos produtos intensivos em recursos naturais exportados gera a entrada de volumosas divisas que por sua vez originam apreciação real da taxa de câmbio, fazendo que a exportação de produtos não intensivos em recursos naturais torne-se mais difícil e facilitando a entrada no mercado doméstico de ampla gama de produtos importados. Esse processo acaba resultando na elevação dos salários e na expansão de dois setores da economia: o intensivo em recursos naturais e o de produtos non tradables (basicamente serviços e construção civil).

A riqueza representada pelos recursos naturais é vista por alguns autores como um tipo diferente de riqueza. Segundo Humphreys, Sachs e Stiglitz (2007, p.3-4), os recursos naturais não precisam ser produzidos. "Eles simplesmente precisam ser extraídos". Assim, prosseguem os autores, como "não é resultado de um processo produtivo, a geração de riqueza natural pode ocorrer independentemente de outros processos produtivos existentes no país", formando "enclaves". ${ }^{5}$ Uma outra característica que faz dos recursos naturais uma "riqueza diferente" para esses autores é o fato de que muitos deles - especialmente petróleo e gás - serem não renováveis. "Do ponto de vista econômico, eles são menos como uma fonte de renda e mais como um ativo." Essas características fariam surgir vários processos políticos e econômicos com efeitos adversos sobre a economia, especialmente o chamado "comportamento rentista" ("rent-seeking behavior").

Com o mesmo tom crítico sobre a produção com base em recursos naturais, Cypher (2014, p.127-30) caracteriza o que ele denomina de "la trampa de "los staples" - a armadilha das matérias-primas, na qual a grande vilã não é a 
queda dos preços das commodities ao longo do tempo, mas sim sua alta volatilidade. Durante o boom dos preços, muitos países e empresas tentam capturar mais rendas por meio de incrementos rápidos da capacidade produtiva. Isso se transforma em um movimento coletivo, o que acaba configurando uma sobrecapacidade por ocasião da operação dos investimentos, determinando o fim do boom dos preços e uma reversão acelerada da tendência altista das commodities. Os produtores não se veem afetados pelo colapso dos preços ao ponto de sair da atividade, pois ampla maioria deles opera em situação de trajetória de dependência (path dependence), ou seja, eles têm um conhecimento específico da área que valorizam e assim ficam esperando a nova tendência altista. Combinada com esse comportamento rentista, a existência de uma débil capacidade de o Estado intervir determina que não existirão forças sociais capazes de construir e alimentar capacidades tecnológicas endógenas. Conclui Cypher que uma nação como essa se fechará (lock-in) na produção de commodities.

A ideia da "armadilha das matérias-primas ou dos produtos básicos" (staples trap) é bem desenvolvida por autores ligados à chamada Staples Theory desenvolvida por Mel Watkins (Watkins's Staples Theory of Economic Growth). Watkins (2006, p.16-17) acredita que os exportadores de produtos básicos - especialmente os que têm poder político - podem estimular uma restritiva "mentalidade exportadora", resultando em excessiva concentração de fatores no setor exportador de commodities primárias e relutância em promover o desenvolvimento econômico interno. Para fugir dessa "staples trap", e obter crescimento econômico sustentado, requerer-se-ia capacidade para mudar as atenções em favor de novos mercados externos e internos, instituições e valores compatíveis com essa mudança, e a "boa sorte de ter evitado a especialização no tipo errado de produto básico" ("the wrong kind of Staples"). A partir do trabalho seminal de Watkins, outros autores desenvolveram o conceito de "staples trap". Um deles é Gago (2014, p.34), que define "Staples trap" como a falta de capacidade de uma economia baseada em recursos naturais para amadurecer para uma economia diversificada e industrializada. Ao especializar-se intensamente na exportação de produtos básicos, essa economia aumentaria sua dependência por investimentos externos diretos e desestimularia a indústria doméstica e a diversificação econômica.

Cimoli, Dosi e Stiglitz (2009, p.556), ao sugerirem princípios para uma política de desenvolvimento bem-sucedida, recomendam: "evite a maldição dos recursos naturais". Segundo os autores, as atividades de produção baseadas em recursos naturais são intensivas em capital e demandam pouca mão de obra qualificada, favorecem a concentração de renda e a corrupção e geram crescimento econômico menor no longo prazo. Aceitam assim a proposição de Sachs e Warner (2001), segundo a qual há evidências empíricas consistentes de que os países com grande abundância de recursos naturais tendem a crescer menos do que os países pobres nesses recursos. ${ }^{6}$ 
É marcante na literatura sobre desenvolvimento na América Latina a proposição de que os países que mais avançaram são aqueles com estrutura produtiva industrial diversificada com atividades intensivas em progresso técnico. (Vieira; Avellar; Veríssimo, 2013; Abelles; Rivas, 2010).

\section{A ideia de recursos naturais como possibilidade para o desenvolvimento}

Por outro lado, Ferranti et al. (2002) procuram alargar o debate, deixando-o com mais nuances. Os autores buscam desfazer "preconceitos e outras preocupações" acerca das atividades baseadas em recursos naturais: “... this report should dispel such prejudices and other concerns about natural resource-based activities" (Ferranti et al., 2002, p.4). Para eles, tais atividades podem ser setores dinâmicos, intensivos em conhecimento, ter elevado crescimento da produtividade, apresentar interações relevantes para trás e para frente na cadeia produtiva, propagar avanços técnicos (technical spillovers), tanto quanto a indústria moderna. Para Ferranti et al. (2002, p.4), a chave do sucesso é completar a abundância de recursos naturais com boas instituições, capital humano e conhecimento. Segundo os autores, a falta desses três últimos elementos é que causa o atraso no desenvolvimento econômico de países da América Latina e não a concentração da estrutura produtiva em atividades centradas em recursos naturais.

Acerca do argumento de que os setores intensivos em recursos naturais teriam baixa eficiência schumpeteriana, ${ }^{7}$ cabe destacar a posição de Wrigth e Czelusta (2002, p.4). Para eles, a grande lição que emerge das discussões acerca do desenvolvimento baseado em recursos naturais é o equívoco de encarar os recursos naturais como "dotação", cuja essência econômica seria fixada pela natureza, e não perceber que é o "processo de aprendizagem” que permite que o potencial econômico desses recursos seja efetivado. A ideia de que recursos naturais não são uma simples "dotação" ou dádiva prontamente oferecida pela natureza, mas que exigem capital, tecnologia, conhecimento para que se tornem uma riqueza de fato, também e defendida por Medeiros (2012, p.22), ao enfatizar a importância de explorar as possibilidades ao longo da cadeia de valor das atividades relacionadas a recursos naturais. ${ }^{8}$

Há outros exemplos, na fronteira tecnológica, que reforçam a eficiência schumpeteriana crescente das atividades intensivas em recursos naturais. Cruz et al. (2014) citam o caso da biobased industry, do destaque crescente que o desenvolvimento de processos para produção de químicos a partir de fontes renováveis tem ganhado no cenário mundial. Os autores identificam uma "verdadeira corrida tecnológica" na Europa e nos Estados Unidos em busca de biocombustíveis de alto desempenho e bioprodutos que substituiriam o petróleo por fontes renováveis, especialmente a biomassa vegetal, criando um novo setor, uma indústria de produtos bioderivados (biobased industry). A demanda para essa indústria está no setor automotivo, ${ }^{9}$ cosméticos, farmacêutico, construção civil e outros setores industriais relevantes. 
Lederman e Maloney (2008) não acreditam que a abundância de recursos naturais afete negativamente o crescimento de longo prazo dos países. Para eles as evidências empíricas demonstram que a tese da "maldição dos recursos naturais" é vaga. ${ }^{10}$ Eles creem, ao contrário, que há algumas evidências de efeito positivo sobre o crescimento, embora admitam que a magnitude disso mantenha-se desconhecida, devido a problemas não resolvidos nas estimativas econométricas.

Para Frankel (2012, p.15), a abundância de recursos naturais não leva necessariamente a um desenvolvimento econômico e político inferior. Segundo o autor, a melhor visão da questão da abundância de commodities é encará-la como uma "faca de dois gumes" ("double-edged sword"). Da mesma forma, Sinnott, Nash e Torre (2010, p.57) afirmam que há um conjunto de problemas associados às commodities que criam significativos riscos, os quais se não forem bem manejados podem afetar de forma adversa a possibilidade de desenvolvimento econômico e institucional dos países. Nessa perspectiva, Medeiros (2012, p.5) acredita que o mais geral problema associado ao desenvolvimento econômico baseado em recursos naturais é o desafio especial colocado para as instituições e particularmente o Estado.

A reação passiva e rentista dos países produtores de matérias-primas e primários diante dos efeitos potencialmente efêmeros dos booms de commodities não deve ser vista como uma regra. Segundo Di John (2011, p. 176), há países que adotam políticas, financiadas com as receitas oriundas das exportações de produtos naturais, para dar suporte à diversificação da estrutura produtiva e ao crescimento de longo prazo, e outros não. Para Cypher (2014, p.131), geralmente não se realiza uma comparação entre as maneiras com que os países lidam com esses booms, se é de uma forma passiva ou se conseguem transformá-los em vantagens aproveitando a oportunidade.

A Teoria dos Produtos Básicos - Staples Theory (ST) - tem sido usada para interpretar a reação não passiva dos países aos booms de commodities. A fundamental proposição da ST é, segundo Watkins (2006, p.8), que as exportações de produtos básicos, ou intensivos em produtos naturais, compõem o setor líder da economia, aquele que determina o ritmo do crescimento econômico. "O desenvolvimento econômico será um processo de diversificação em torno dessa base exportadora." Segundo o autor, o conceito central da ST está expresso nos efeitos, impactos, da atividade exportadora de commodities sobre a economia doméstica e a sociedade. Do ponto de vista econômico, os seguintes fatores determinam os efeitos do setor exportador de commodities: sua demanda pelos diversos fatores; sua demanda por produtos intermediários; as possibilidades de processamento posterior; o nível de distribuição de renda induzido pelo setor exportador. Inspirando-se em Hischman (1958, cap.6), Watkins (2006, p.9) aponta que a extensão da diversificação produtiva ao redor da base exportadora depende dos efeitos dos fluxos de renda oriundos dessa base sobre o investimento doméstico, avaliado segundo três efeitos encadeadores (linkage effects): 
encadeadores para trás (backward linkage), encadeadores para frente (forward linkage), encadeadores da demanda final (final demand linkage). ${ }^{11}$

Entretanto, como aponta Haley (2014, p.76), Watkins vai mais além, e também destaca a influência do setor de produtos intensivos em recursos naturais sobre a natureza do empreendedorismo, ${ }^{12}$ da absorção tecnológica e da inovação. Isso significa que a ST não considera apenas as conexões físicas e financeiras do setor de produtos intensivos em recursos naturais, mas também sua influência sobre as instituições, os valores e a política. Pata a ST de Watkins, como salienta Haley (2014, p.76), o desenvolvimento sustentável a partir de uma base de produtos intensivos em recursos naturais requer instituições econômicas que apoiem a capacidade da estrutura produtiva de dar respostas e se adaptar a mudanças econômicas globais. ${ }^{13}$

Cypher (2014, p.133), valendo-se das explicações da Staples Theory, argumenta que países como Canadá, Austrália, Nova Zelândia, Noruega, Finlândia conseguiram ter forte reação induzida da oferta ao crescimento das exportações de intensivos em recursos naturais, ou seja, ocorreram investimentos complementares em amplo leque de indústrias nacionais, fazendo que os estímulos positivos dos termos de troca favoráveis fossem transmitidos para dentro, criando um círculo virtuoso de reinversão, diversificação, crescimento do emprego e expansão do mercado interno.

Em estudo recente (dezembro de 2013) da Divisão de Recursos Naturais e Infraestrutura da Comissão Econômica para América Latina e Caribe (Cepal, 2013), afirma-se que é fundamental assegurar a participação pública em rendas derivadas de recursos naturais, e também estabelecer uma "governança dos recursos naturais" que compreenda políticas soberanas dos países sobre a propriedade, apropriação e distribuição dos recursos naturais para maximizar sua contribuição ao desenvolvimento. ${ }^{14}$

\section{Estratégias de desenvolvimento econômico para a América Latina e recursos naturais}

Nos anos 2000, a América Latina depara com importantes mudanças em seu contexto histórico - uma nova realidade global. Uma dessas mudanças decorre do que a China representa para a economia mundial. Ela se converteu na segunda maior economia do Planeta, e está a passos largos para se tornar provavelmente em alguns anos a primeira. Essa posição tão relevante e rapidamente conquistada pela China - algo como dez anos - fez Castro (2008) chamar o mercado global de "mercado sinocêntrico". Para ele a presença chinesa é mais do que uma mudança quantitativa, é também uma transformação qualitativa: "Há seis anos (2005) eu comecei a suspeitar que a emergência chinesa representava uma ruptura na trajetória do sistema econômico mundial" (Castro, 2011). A importância econômica da China não é refletida apenas pelo gigantismo do seu PIB e do montante de suas transações comerciais. Como demonstram Cacciamali, Bobik e Celli Jr. (2012, p.100), os indicadores de ciência e tecnologia 
mostram forte crescimento na China. Examinado esse fenômeno inédito, Pérez $(2010$, p.125) afirma que a China e a Índia mostram como pertencer à periferia já não se constitui em uma "dependência" estática, e sim muita mais provavelmente dinâmica.

O fenômeno chinês tem produzido forte demanda por recursos naturais. Os preços das commodities de origem primárias e produtos industriais intensivos em recursos naturais adquiriram trajetória crescente. ${ }^{15}$

A forte presença da China no comércio internacional como produtora de manufaturados e consumidora de commodities não impõe à América do Sul um destino, mas abre uma oportunidade. É assim que pensa Pérez (2010, p.128) quando afirma que a natureza da competição com a China e outros asiáticos no mercado global é uma das realidades a enfrentar seja qual for a estratégia de desenvolvimento da América Latina. A Ásia enfrenta escassez de matérias-primas e energia, o que permite que a América Latina exporte para lá quantidades crescentes de minerais, produtos agrícolas e energia a preços ascendentes. A América Latina tem dificuldade cada vez maior de competir no segmento da indústria de montagem. Entretanto, como enfatiza Pérez (2010, p.128), sua rica dotação de recursos naturais oferece uma "janela de oportunidade" para "especializar-se em indústrias de processo". ${ }^{16}$ Pérez (2010, p.143) acredita que usando o aumento de renda para melhorar o perfil tecnológico das exportações e fomentar a capacidade da população de criar riqueza, a América Latina pode especializar-se em materiais feitos sob medida, alimentos sofisticados e outros produtos naturais, enquanto se prepara para ter um bom posicionamento na $6^{\mathrm{a}}$ Revolução Tecnológica.

Pérez $(2010$, p.125) aponta que as "condições atuais" criam "janela de oportunidade" para permitir que o "desenvolvimento baseado em recursos naturais" seja uma "rota de desenvolvimento a ser empreendida" pelos países da AL. Essas "condições atuais" estariam representadas, além da emergência da China, pelos "processos de hipersegmentação" desencadeados pelo "Paradigma das TIC", do qual a globalização seria um elemento intrínseco. Da mesma forma, a ideia de "nicho de "especialidade" se relacionaria frequentemente com segmentos de matérias-primas e produtos primários (cafés do tipo premium, aços especiais etc.). Uma das consequências dessa complexa forma dos mercados, destaca a autora, seria ter que deixar de considerar a "industrialização" como o topo do desenvolvimento e considerar a necessidade de criar termos como "tecnologização" para caracterizar posições mais vantajosas no quadro dos mercados globais.

Barletta, Robert e Yoguel $(2012$, p.58) são críticos à proposta de Carlota Pérez. Não acreditam que o desenvolvimento de nichos de mercado seja uma forma efetiva para obter mudança estrutural que origine catch-up. Para eles, só os setores que apresentam simultaneamente eficiência keynesiana e schumpeteriana ${ }^{17}$ têm possibilidade de impulsionar a mudança estrutural. Os autores, 
corretamente, alertam para o fato de que a mudança estrutural requer o surgimento de atividades econômicas que gerem uma massa crítica de empresas que tenha grande impacto em termos de emprego, produto e produtividade. Barletta, Robert e Yoguel (2012, p.59) também argumentam que a disponibilidade de recursos naturais não constitui em si mesma uma vantagem para criar atividades relacionadas de alto conteúdo tecnológico e que as evidências parecem estar em sentido contrário. Eles citam o fato de que o desenvolvimento de sementes geneticamente modificadas está na mão de transnacionais e que componentes eletrônicos e softwares para equipamentos da agricultura de precisão são importados pelos países da América Latina.

Carlota Pérez (2012) procura dar resposta a essas críticas, detalhando sua visão de desenvolvimento para a América Latina. A autora argumenta que não se trata de uma rota ideal, e sim de encontrar um caminho que signifique acumular capacidade com base nas condições disponíveis. Dentro dessas condições, ela identifica três novas delas, próprias da atual fase do capitalismo, que viabilizariam sua proposta: a) a possível complementaridade da América Latina com a Ásia, que teria demanda crescente para insumos e alimentos (eficiência keynesiana); b) o aumento da possibilidade de inovação local nas cadeias de produção de recursos naturais, por meio das TIC e outras tecnologias radicais, como biotecnologia e nanotecnologia (eficiência schumpeteriana); c) mudança das tendências de preços relativos entre produtos fabricados e recursos naturais, com a possibilidade dos primeiros caírem ("commoditização" de produtos industriais) em relação aos segundos.

A noção de recursos naturais como oportunidade e não como "maldição" também é partilhada por outros autores que abordam a temática do desenvolvimento da América Latina, tais como Bielschowsky (2012), Furtado (2008) e Castro (2011).

Bielschowsky (2012), analisando estratégias de desenvolvimento para o Brasil, propõe três motores do desenvolvimento econômico: consumo de massa, recursos naturais e infraestrutura. $\mathrm{O}$ autor sustenta que sua formulação é adequada porque está dentro de um "processo histórico viável”, já que se encontra inscrita na lógica da operação da economia brasileira e tem a possibilidade de alcançar razoável coesão social. Mas, para que isso ocorra, as atividades baseadas em recursos naturais "não podem ser meros enclaves de onde saíam as matérias-primas sem deixar rastro de emprego, progresso técnico e bem-estar social". (Bielschowsky, 2012, p.740-1).

Segundo Furtado (2008, p.37, 39, 40 e 44), o crescimento recente das economias com grande população da Ásia gera "uma oportunidade extraordinária” para os países com recursos naturais abundantes. O Brasil possuiria, nesse contexto, uma "condição singular": tem "amplo leque de recursos naturais e uma herança industrial solidamente estruturada”. Furtado vê como potencialmente exitosa para o caso brasileiro uma estratégia de desenvolvimento sustentada por um "processo de dinamização industrial a partir da base primária". 
Castro (2011) enxerga o Brasil como um híbrido industrial e agrícola. Para ele, parte relevante da indústria brasileira não é competitiva porque o sistema industrial chinês é mais eficiente, e recomenda quais seriam os setores a fortalecer: "seriam setores protegidos pela especificidade de nossos recursos naturais, por costumes, estrutura industrial e demanda. Áreas em que o chinês não está e nem vai estar".

Em que pese o exemplo de países bem-sucedidos em sua estratégia de desenvolvimento baseada em recursos naturais e as possibilidades de que políticas de Estado reduzam os riscos e realizem o potencial dos setores intensivos em recursos naturais, existe marcante controvérsia sobre o papel dos recursos naturais no desenvolvimento da América Latina. Cacciamali, Bobik e Celli Jr. (2012, p.93) alertam para o risco de uma volta da especialização das economias latino-americanas em commodities, "mesmo com maior densidade tecnológica e com alterações ambientais", dificultar as "possibilidades futuras de desenvolvimento dos países latino-americanos".

O crescente e intenso protagonismo chinês na economia internacional a partir dos anos 2000 está associado a um aumento da participação relativa de produtos primários e manufaturados intensivos em recursos naturais no conjunto das exportações. Para a América Latina, e especialmente para o Brasil, esse aumento foi mais intenso. ${ }^{18}$

Teríamos então um processo clássico e claro de primarização, ou reprimarização acompanhada de desindustrialização, da economia brasileira como efeito adverso da emergência chinesa? Barbosa et al. $(2014$, p.16) procuram responder essa indagação. Para eles, caracterizar o impacto chinês sobre a economia brasileira não é tão fácil. Está claro que os superávits comerciais brasileiros com a China derivam da sua diversificada oferta de commodities agrícolas e minerais, e que há uma substancial expansão do déficit comercial brasileiro com a China na indústria manufatureira, especialmente máquinas, equipamentos e eletrônicos. Entretanto, prosseguem Barbosa et al. (2014, p.16), a indústria brasileira mantém um razoável nível de diversificação, assegurado pelo tamanho do seu mercado interno e pelo seu potencial exportador especialmente para a América do Sul.

Cypher (2014) destaca um aspecto importante quando se discute o desenvolvimento da América Latina: as diferenças intra-regionais. $\mathrm{O}$ autor acredita que no geral a América Latina não tem atualmente conseguido um processo de crescimento baseado na produção e no investimento doméstico, e sim na exploração e exportação de matérias-primas, o que reforçaria a hipótese da primarização ou reprimarização. No entanto, Cypher (2014, p.135-7) julga os casos da Argentina e do Brasil como distintos, nos quais essa hipótese não se aplicaria. No caso da Argentina, a recuperação do crescimento econômico durante o auge das commodities teria sido um processo equilibrado entre o mercado doméstico e as exportações. No caso do Brasil, diferentemente de outros países sul-americanos, o país teria buscado uma estrutura industrial competitiva por meio de uma política industrial ativa e da construção de um sistema nacional de inovação. 
O Chile também deve ser citado quando se pensa em diferenças existentes na América Latina. Uma parte relevante da literatura, como pode ser exemplificado com Frankel (2012, p.15) e Wright e Czelusta (2002, p.1), aponta o Chile como um caso moderno bem-sucedido de desenvolvimento baseado em recursos naturais. De fato, o Chile se destaca por suas taxas de crescimento elevadas nas duas últimas décadas e pelo aumento de sua renda per capita.

Quando se pensa em grandes economias da América Latina, como o Brasil, a estratégia de desenvolvimento baseada em recursos naturais é, por muitos, total ou parcialmente preterida em favor de estratégias que tenham como centro a industrialização e como referência ou o modelo dos Estados Unidos ou o modelo asiático. ${ }^{19}$ Cacciamali, Bobik e Celli Jr. (2012, p.103), diante das características da economia brasileira, acreditam que um "novo modelo econômico" "terá perfil concorrente com a estrutura econômica norte-americana, pois deverá contemplar a combinação de indústrias de alto valor agregado, autossuficiência e diversidade energética e alta produtividade na produção de alimentos e outras commodities". Bresser-Pereira e Gala (2010, p.13) julgam que os países da América Latina, incluindo o Brasil, estão sofrendo da "doença holandesa ou maldição dos recursos naturais", que produz "sobreapreciação crônica da taxa de câmbio", conduzindo esses países à desindustrialização. Então, segundo os autores, tratar-se-ia de reestabelecer uma "taxa de câmbio de equilíbrio industrial" - desvalorização cambial - que faria retomar o processo de industrialização. Rocha (2012, p.68), avaliando a proposta de Bresser-Pereira e Gala, afirma que ela é equivalente à "retomada da trajetória asiática com quarenta anos de retardo, agravada pela inadequada dotação de fatores".

A mudança da realidade econômica global, representada principalmente pelo fenômeno chinês, globalização e transformações tecnológicas e mercadológicas trazidas pela era das TIC, reestabeleceu, de maneira mais específica, a importância do debate em torno do papel da abundância de recursos naturais no desenvolvimento, e, de maneira mais geral, recolocou em posição de destaque o debate sobre desenvolvimento econômico da América Latina.

\section{Considerações finais}

A clássica controvérsia sobre a contribuição dos recursos naturais para o desenvolvimento dos países da América Latina, iniciada com a hipótese Prebisch-Singer e municiada pela Staples Theory, tem agora novos ingredientes trazidos pelas alterações do contexto histórico desses países. Entre esses ingredientes está um conjunto de perguntas, questões, presentes na literatura e que ensejam novas investigações e reflexões. "Será que as commodities atuais são semelhantes às do passado?" (Cacciamali, Bobik; Celli Jr., 2012, p.93). "Há ou não um inescapável dilema entre a velha economia baseada em recursos naturais e a economia do século XXI intensiva em conhecimento?” (Ferranti et al., 2002, p.2). "Para superar a menor elasticidade renda da demanda dos bens das atividades intensivas em recursos naturais, como evoluir em direção à especialização 
em atividades mais intensivas em tecnologia que permitam a criação de novos produtos e portanto a conquistas de novos mercados?" (Rocha, 2012, p.67-8).

O espaço para o surgimento de respostas a essas questões e o aparecimento de novas indagações no debate em torno do papel dos recursos naturais no desenvolvimento econômico da América Latina ampliou-se. A revelação desse papel é determinante na formulação de estratégias de desenvolvimento econômico dos países da região, sejam elas uma escolha plena, sejam elas uma escolha obtida por exclusão.

A abundância de recursos naturais pode se manifestar como uma "faca de duplo fio", podendo ou não levar ao desenvolvimento. Os países devem se preparar para fugir das armadilhas que afetaram países produtores de commodities no passado. Um ponto central da questão do desenvolvimento baseado em recursos naturais diz respeito ao desafio colocado para as instituições e principalmente para o Estado. É necessário garantir adequada apropriação e aplicação públicas das rendas provenientes de recursos naturais. ${ }^{20}$

No caso do Brasil, diante do crescimento significativo da participação de produtos primários e de manufaturados intensivos em recursos naturais na pauta exportadora e do aumento do seu market-share global, fala-se em reprimarização e desindustrialização como resultados adversos da emergência chinesa. Deve-se ter cuidado com diagnósticos açodados, que não ponderam o fato de que o Brasil mantém estrutura industrial diversificada, assegurada pelo seu mercado interno robusto e sua capacidade exportadora regional.

Há ainda uma ponderação importante a fazer quando se pensa em estratégias de desenvolvimento para a totalidade da América Latina: suas diferenças intra-regionais. Há distinções que condicionam o tipo de resposta que cada país poderia dar aos ciclos altistas das commodities ${ }^{21}$ e o tipo de inserção externa que poderia ser ambicionada.

As oportunidades futuras de crescer tendem a estar condicionadas pela estrutura produtiva vigente. As escolhas, as estratégias devem estar inseridas em uma trajetória histórica possível, que considerem certos parâmetros de funcionamento da estrutura produtiva nacional e gerem coesão social. Elas devem criar novas vantagens econômicas dinâmicas, para as quais a inovação é determinante, e não debilitar posições já alcançadas. Não obstante a diversificação produtiva deva ser um objetivo, não se deve apostar em todos os setores. Proteger setores nos quais a produtividade cresce abaixo da dos concorrentes tende a ser improducente. Mirar o caso chinês pode ser um esforço que tenha décadas de atraso, agravado pela ausência de salário e de qualificação da mão de obra em padrões asiáticos. Obter os níveis salariais baixos (via forte desvalorização cambial, por exemplo) com qualificação alta dos chineses pode não ser mais tolerável do ponto de vista político para países como o Brasil e Argentina.

As escolhas plenas estão limitadas. Mas isso não quer dizer que os limites não se movam. As transformações na divisão internacional do trabalho e as 
inovações tecnológicas criam oportunidades para promover o tripé do desenvolvimento econômico - crescimento, igualdade social e alto padrão tecnológico. Porém essas oportunidades não se efetivam naturalmente, elas necessitam para isso de políticas públicas bem concebidas e operadas, o que ressalta os desafios que continuam a existir para as instituições em geral e o Estado em particular na América Latina.

\section{Notas}

I Países asiáticos, notadamente a China, passaram a disputar mercados, com produtos manufaturados, inclusive os de tecnologia elevada, diretamente com países do núcleo capitalista.

2 Segundo Engerman e Sokoloff (2012, p.9-11), logo após a vitória britânica sobre os franceses na Guerra dos Sete Anos (1756-1763), estabeleceu-se um vibrante debate público na Inglaterra acerca de qual parte do território colonial francês seria tomada: a pequena ilha caribenha de Guadalupe ou o Canadá. Ainda de acordo com os autores, o Haiti era provavelmente a sociedade mais rica do mundo, se considerada fosse a renda per capita do ano de 1790.

3 "Os projetos de mineração, ao invés de repor o capital neles empregado, juntamente com os lucros normais do capital, comumente absorvem tanto o capital como o lucro. Eis por que são esses os projetos aos quais [...] um legislador prudente, que desejar aumentar o capital de sua nação, menos deveria escolher para conceder qualquer estímulo extraordinário ou para canalizar para eles uma parcela de capital superior àquela que espontaneamente neles se aplicaria" (Smith, 1983, p.54).

4 Segundo Castro (2008), por muitos anos o mainstream empenhou-se em negar os problemas que tendem a enfrentar economias emergentes centradas em recursos naturais. Considerando-se que não se possa entender o chamado mainstream como um corpo único e uniforme, Castro parece estar se referindo à visão liberal convencional de que o mercado internacional livre conduziria os países para a especialização da sua estrutura produtiva de acordo com suas vantagens comparativas. A visão liberal convencional, baseada na Teoria das Vantagens Comparativas de David Ricardo, tem sustentado que a especialização produtiva dos países ricos em recursos naturais em atividades intensivas nesses recursos colocaria tais países em posição de extrair o máximo de ganhos que o comércio internacional pudesse oferecer. Assim a abundância de recursos naturais seria uma vantagem comparativa no comércio internacional que representaria uma verdadeira "benção" para o desenvolvimento econômico da América Latina.

5 As atividades intensivas em recursos naturais seriam "enclaves", para Humphreys, Sachs e Stiglitz (2007, p.4), na medida em que elas podem ocorrer sem importantes interações (linkages) com outros setores da economia e sem a participação de grande segmento da força de trabalho doméstica.

6 "Natural resource abundant countries systematically failed to achieve strong export led growth or other kinds of growth" (Sachs; Warner, 2001, p.838).

$7 \mathrm{O}$ conceito de eficiência schumpeteriana está mais adiante apresentado. 
8 De acordo com Medeiros (2012, p.22), o sistema de transporte e as tecnologias necessárias para a exploração dos recursos naturais colocam diferentes desafios e criam oportunidades para a diversificação. Ele cita o caso da exploração de gás, pela Rússia, na região do Ártico, que pelas dificuldades pode ser uma atividade propulsora de investimentos com alta tecnologia, de pesquisas tecnológicas e, se uma ampla política industrial favorecer os produtores locais de equipamentos para essa exploração, de novas oportunidades tecnológicas. Poderíamos acrescentar o caso da exploração brasileira de petróleo na camada pré-sal também como exemplo para esse raciocínio.

9 Há grandes empresas automobilísticas demonstrando interesse no uso de bioprodutos, como óleos renováveis em substituição parcial ao petróleo, como fibras naturais em compósitos plásticos e como resinas termoplásticas renováveis. Os biomateriais podem oferecer propriedades - leveza, durabilidade, flexibilidade - que melhorem o desempenho do automóvel (Cruz et al., 2014, p.13).

10 "Clearly the resource curse remains elusive. The cross-country econometric evidence remains weak" (Lederman; Maloney, 2008, p.7).

11 A diversificação da economia será maior quando os insumos demandados pelo setor exportador de produtos básicos envolverem fatores e tecnologia que permitam sua produção doméstica; quando houver aumento do valor adicionado das exportações (possibilidade de processamento doméstico dos produtos básicos); quando houver indução de investimentos domésticos para a produção de bens de consumo, o que depende do tamanho do mercado doméstico, que é determinado pelo nível de renda agregada, média e de sua distribuição (Watkins, 2006, p.9-10). Assim quanto mais fracas as conexões, encadeamentos (linkages), maior a dependência da economia ao setor exportador de recursos naturais, mais próxima está essa economia da staples trap.

12 Segundo Watkins (2006, p.11), a expansão do setor exportador de produtos intensivos em recursos naturais cria oportunidades para o investimento doméstico que podem ou não ser exploradas. Dessa forma, para Watkins, o empreendedorismo - visto por ele como a habilidade de perceber e explorar oportunidades de mercado - é um fator-chave.

13 Isso introduz o valor da capacidade de recuperação e da adaptabilidade da estrutura produtiva e a necessidade de considerar fatores como os ativos ligados ao conhecimento, o acesso à educação, a natureza do poder político, e a habilidade de usar e gerar novas tecnologias (Haley, 2014, p.76).

14 Para Cepal (2013), a adequada gestão macroeconômica das rendas provenientes dos recursos naturais deveria destacar a importância de institucionalizar o uso de fundos de estabilização, fundos de inversão, regras macrofiscais e acumulação de reservas, entre outros mecanismos de poupança, para amenizar os efeitos deletérios da valorização cambial e para obter fôlego fiscal destinado à política anticíclica. A Cepal também destaca a importância de políticas para regular a entrada extraordinária de divisas e o fluxo de capitais de curto prazo para combater os efeitos cambiais indesejados sobre a estrutura produtiva, além da necessidade imperiosa de aplicar as rendas dos recursos naturais para a formação de capital humano, inovação, infraestrutura e outros investimentos de longo prazo que possibilitem a diversificação da base industrial e exportadora.

15 De acordo com dados da Organização Mundial do Comércio (WTO, 2015), as importações de produtos agrícolas, combustíveis e minerais por parte da China eram 53,4 bilhões de dólares em 2000, aumentaram rapidamente para 164,8 bilhões em 
2005, alcançaram 483,3 bilhões de dólares em 2010, e continuaram sua trajetória ascendente ao atingir 709,8 bilhões de dólares em 2013. Com base em informações do Fundo Monetário Internacional (IMF, 2015), apresenta-se a evolução recente do índice de preços das commodities primárias (2005 = base 100, em US\$): em 2008 aumentou para 172,4; em 2009, em decorrência da crise financeira internacional, caiu para 120,7; posteriormente seguiu trajetória de recuperação e em 2013 já alcançava 183,3; no quarto trimestre de 2014 sofreu nova inflexão e desceu para 145,5; em janeiro de 2015, novo tombo, reduzindo-se para 114,7. Deve-se ressalvar que a queda desse índice foi causada majoritariamente pelo preço das commodities energéticas, especialmente o petróleo. $\mathrm{O}$ índice de commodities primárias não energéticas sofreu uma queda moderada de 162,3 em 2014 para 145,7 em janeiro de 2015. O mesmo índice para commodities energéticas apresentou expressiva redução de 177,4 em 2014 para 96,5 em janeiro de 2015. De qualquer forma, o índice de preço das commodities primárias ainda segue bem acima dos níveis do início da década de 2000 (no ano de 2000 esse índice estava ao redor de 60).

16 "Indústria de processo" corresponde à atividade que transforma diretamente matérias-primas por meio de métodos químicos, elétricos, calor ou outros (aço, papel, gasolina, molho de tomate, plásticos) e a serviços como telecomunicações. A diferença com a "indústria de montagem" é que no primeiro caso a produção ocorre "dentro" do sistema de equipamentos e a mão de obra supervisiona e apoia o processo ao invés de executá-lo (Pérez, 2010, p.128).

17 Eficiência keynesiana refere-se a um padrão de comércio internacional sustentado em produtos com alta elasticidade-preço da demanda, que geram mercados extensos e aumento da divisão do trabalho, permitindo o surgimento de economias de escala. A eficiência shcumpeteriana refere-se a um padrão de especialização no qual a capacidade de desenvolvimento de novas tecnologias, a inovação, a mudança técnica são características-chave. Esse tipo de eficiência está relacionado a produtos com alta intensidade tecnológica e elevada produtividade, com ganhos de escala crescentes, com transbordamentos (spillovers) e fortes cadeias produtivas. Em oposição, o padrão de comércio internacional baseado em eficiência de dotação reflete vantagens estáticas que resultam da abundância de fatores (Barletta; Pereira; Yoguel, 2013, p.798).

18 Dados da UN Contrade, tabulados por Cunha et al. (2011), revelam que a participação dos produtos primários e manufaturados intensivos em recursos naturais era de 26,5\% das exportações mundiais em 2000 e passou para 30,9\% em 2009 (aumento de 17\%). Para a América Latina essa elevação foi mais intensa no período, de 43,5\% para 58,3\% (aumento de 34\%). Quando se examina o caso brasileiro, constata-se que a intensidade da elevação é ainda maior, pois a participação subiu de 46,6\% em 2000 para 64,2\% em 2009 (aumento de 38\%).

19 Entre os que argumentam a favor dessas estratégias alternativas a dos recursos naturais está aqueles que creem no diagnóstico de que mesmo economias grandes como a do Brasil estariam sofrendo de um processo de reprimarização e de instalação da doença holandesa, como é o caso de Bresser-Pereira e Gala (2010).

$20 \mathrm{O}$ que inclui a gestão macroeconômica dessas rendas, institucionalizando fundos de estabilização, fundos para investimento e acumulação de reservas, além da utilização de recursos prioritariamente na educação/formação profissional, inovação e infraestrutura. Assim aumenta-se a possibilidade de estabilização econômica no curto prazo e diversificação da base produtiva no longo prazo. 
21 A esse respeito, vale ressaltar as diferenças entre Chile e Venezuela, como casos opostos no que diz respeito aos efeitos de estruturas produtivas baseadas em recursos naturais.

\section{Referências}

ABELLES, M.; RIVAS, D. Growth versus development: different patterns of industrial growth in Latin America during the 'boom' years. S. 1.: Cepal, UN, 2010.

BARBOSA, A. de F. et al. Brazil-China Economic Relations: Trade Pattern and China Investment Profile in Brazil. In: CONFERENCE CHINA-LUSOPHONE COUNTRIES RELATIONS, 1, Macau, 2014.

BARLETTA, F.; PEREIRA, M.; YOGUEL, G. Schumpeterian, Keynesian, and Endowment efficiency: some evidence on the export behavior of Argentinian manufacturing firms. Industrial and Corporate Change, v.23, n.3, p.797-826, aug. 2013.

BARLETTA, F.; ROBERT, V.; YOGUEL, G. Algunos comentarios sobre el artículo "dinamismo tecnológico e inclusión social mediante una estrategia basada en los recursos naturales", de Carlota Pérez. Revista Econômica, Niterói, v.14, n.2, p.55-61, dez. 2012 .

BIELSCHOWSKY, R. Estratégia de desenvolvimento e as três fontes de expansão no Brasil: um desenho conceitual. Economia e Sociedade, Campinas, v.21, n. esp., p.72947, dez. 2012.

BRESSER-PEREIRA, L. C.; GALA, P. Macroeconomia estruturalista do desenvolvimento e novo desenvolvimentismo. Revista de la CEPAL, n.100, jan. 2010.

CACCIAMALI, M. C.; BOBIK, M.; CELLI JUNIOR, U. Em busca de uma nova inserção da América Latina na economia global. Estudos Avançados, São Paulo, v.26, n.75, p.91-110, 2012.

CASTRO, A. B. From semi-stagnation to growth in a sino-centric market. Revista de Economia Política, São Paulo, v.28, p.15-45, 2008.

O Brasil tem que se reinventar para tratar com a China. Folha de S.Paulo, 11 de abril de 2011. (Entrevista concedida à jornalista Claudia Antunes). Disponível em:<http://wwwl.folha.uol.com.br/fsp/mundo/ftl104201109.htm>. Acesso em: 15 fev. 2015.

CEPAL. Recursos naturales: situación y tendências para uma agenda de desarrollo regional em América Latina y Caribe. Santiago: Cepal, 2013.

CIMOLI, M.; DOSI, G.; SITIGLITZ, J. E. The future of industrial policies in the new millennium: toward a knowledge-centered development agenda. In: (Ed.)

Industrial Policy and Development: the political Economy of capabilities accumulation. Oxford: Oxford University Press, 2009. p.541-60.

CRUZ, A. C. et al. Química verde na ótica dos agentes de mercado. BNDES Setorial, Rio de Janeiro, n.39, p.5-54, mar. 2014.

CUNHA, A. M. et al. A intensidade tecnológica das exportações brasileiras no ciclo recente de alta nos preços das commodities. Indicadores Econômicos FEE, Porto Alegre, v.39, n.3, p.47-70, 2011. 
CYPHER, J. Neoextraccionismo y primarización: términos de intercambio em América del Sur. In: GIRÓN, A. (Coord.) Democracia, financiarización y neoextraccionismo ante los desafios de la industrialización y el mercado de trabajo. México: Universidad Nacional Autónoma de México, Instituto de Investigaciones Económicas, 2014. p.117-41.

DI JOHN, J. Is There a Resource Curse? A Critical Survey of Theory and Evidence. Global Governance, n.17, p.167-84, 2011..

ENGERMAN, S.; SOKOLOFF, K. Economic Development in the Americas since 1500: endowments and institutions. Cambridge, UK: Cambridge University Press, 2012.

FERRANTI, D. de et al. From natural resources to the knowledge economy. Washington, D.C.: The World Bank, 2002. (World Bank Latin American and Caribbean Studies).

FRANKEL, J. A. The natural resource curse: a survey of diagnoses and some prescriptions. John F. Kennedy School of Government, Harvard University, 2012. Disponível em: <http://web.hks.harvard.edu/publications>. Acesso em: 10 jun. 2014.

FURTADO, J. Muito além da especialização regressiva e da doença holandesa: oportunidades para o desenvolvimento brasileiro. Novos Estudos CEBRAP, n.81, jul. 2008.

GAGO, A. D. The staples trap in developing countries. In: STAMFORD, J. (Ed.) The Staples Theory@50: reflections on the lasting significance of Mel Watkins' “a staple theory of economic growth". S. 1.: Canadian Centre for Policy Alternatives. 2014. p.34-40.

HALEY, B. The staple theory and the carbono trap. In: STAMFORD, J. (Ed.) The Staples Theory @50: reflections on the lasting significance of Mel Watkins' "a staple theory of economic growth". S. 1.: Canadian Centre for Policy Alternatives. 2014. p.75-9.

HISCHMAN, A. The strategy of economic Development. New Haven: Yale University Press. 1958.

HUMPHREYS, M.; SACHS, J.; STIGLITZ, J. (Ed.) Escaping the resource curse. New York: Columbia University Press. 2007.

IMF - INTERNATIONAL MONETARY FUND. Research. Disponível em: <http:// www. imf.org/external>. Acesso em: 18 fev. 2015.

KALDOR, N. Further essays on Applied Economics. London: Duckworth, 1978.

LEDERMAN, D.; MALONEY, W. F. In search of the missing resource curse. The World Bank, 2008. (Policy research working paper, n.4766).

LEDERMAN, D.; OLARREAGA, M.; PERRY, G. (Org.) China's and India's challenge to Latin America. Washington, DC: World Bank, 2008.

MEDEIROS, C. A. de. Natural resources nationalism and development strategies. 2012. Disponível em: <http://grupolujan-circus.blogspot.com.br/2012/06/natural-resourses-nationalism-and.html>. Acesso em: 14 jul. 2014.

OCAMPO, J. A.; PARRA-LANCOURT, M. The terms of trade for commodities since the mid-19th. Journal of Iberian and Latin America Economic History, v.28, n.1, p.1143,2010 .

PÉREZ, C. Dinamismo tecnológico e inclusión social em América Latina: una estrategia de desarrollo productivo basada en los recursos naturales. Revista de la CEPAL, n.100, abr. 2010. 
PÉREZ, C. Réplica a los comentarios. Revista Econômica, Niterói, v.14, n.2, p.73-81, dez. 2012.

PREBISCH, R. O desenvolvimento Econômico da América Latina e seus principais problemas. Revista Brasileira de Economia, Rio de Janeiro, v.3, 1949.

ROCHA, C. F. Comentários a “una visión para America Latina: dinamismo tecnológico e inclusión social mediante una estrategia basada en los recursos naturales", de Carlota Pérez: a lei de Engel. Revista Econômica, Niterói, v.14, n.2, p.63-72, dez. 2012.

SACHS, J.; WARNER, A. Natural resources and economic development: the curse of natural resources. European Economic Review, v.45, p.827-38, may 2001.

SINGER, H. The distribution of gains between investing and borrowing countries. The American Economic Review, v.40, n.2, p.473-85, may 1950.

SINOTT, E.; NASH, J.; DE LA TORRE, A. Natural resources in Latin American and Caribean: Beyond Booms and Busts. Washington: The World Bank, 2010.

SMITH, A. A riqueza das nações: investigação sobre sua natureza e suas causas. São Paulo: Abril Cultural, 1983.

VIEIRA, F. V.; AVELLAR, A. P. M. de; VERÍSSIMO, M. P. Indústria e crescimento: análise de painel. São Paulo: Núcleo de Economia Regional e Urbana da Universidade de São Paulo, 2013. (TD Nereus 06-2013).

WATKINS, M. A Staple Theory of Economic Growth (1963). In: GRANT, H.; WOLFE, D. (Ed.) Staples and Beyond: select writings of Mel Watkins. Montreal, Canada: McGrill-Queens University Press, 2006. p.5-29.

WRIGHT, G.; CZELUSTA, J. Resource-based economic growth, past and present. Stanford, CA: Stanford University, 2002.

WTO - WORLD TRADE ORGANIZATION. Time series. Disponível em: <http:// stat.wto.org/statisticalProgram>. Acesso em: 18 fev. 2015.

RESUMO - O objetivo geral deste artigo é identificar e interpretar potencialidades e ris$\cos$ da maior concentração da estrutura produtiva em setores intensivos em recursos naturais. Como objetivo mais específico, procura-se verificar se as condições atuais da economia global criaram oportunidades para uma estratégia de desenvolvimento baseada em recursos naturais para os países da América Latina. A presença global da China, a revolução das TIC e a globalização consolidaram um quadro de mudanças que podem redefinir as possibilidades da estrutura produtiva baseada em recursos naturais. Os países da região devem se preparar para fugir das armadilhas que afetaram países produtores de commodities no passado. Um ponto central da questão do desenvolvimento baseado em recursos naturais diz respeito ao desafio colocado para as instituições e principalmente para o Estado.

PALAVRAS-CHAVE: Desenvolvimento econômico e recursos naturais, Maldição dos recursos naturais, Recursos naturais e América Latina, Estratégias de desenvolvimento econômico. 
ABSTRACT - The purpose of this article is to identify and interpret the potential and risks of a more concentrated production structure in natural resources-intensive industries. In particular, it attempts to assess if the current conditions of the global economy have created opportunities for a development strategy based on natural resources in Latin America. The global presence of China, the ICT revolution and globalization have consolidated a framework of change that can redefine the possibilities of a productive structure based on natural resources. Latin American countries must be prepared to avoid the pitfalls that affected commodities-producing countries in the past. A central point of development based on natural resources is the challenge to institutions and especially to the State.

KEYWORDS: Economic development and natural resources, Curse of natural resources, Natural resources and Latin America, Economic development strategies.

João Batista Pamplona é professor do Programa de Pós-Graduação em Administração da Universidade Municipal de São Caetano do Sul, e do Programa de Pós-Graduação em Economia Política e do Departamento de Economia da Pontifícia Universidade Católica de São Paulo. @-pamplonajb@uol.com.br

Maria Cristina Cacciamali é professora da Faculdade de Economia, Administração e Contabilidade da Universidade de São Paulo. Professora do curso de Pós-Graduação em Integração da América Latina (Prolam/USP). @ - cciamali@uol.com.br

Recebido em 9.3.2015 e aceito em 18.5.2015.

I Programa de Pós-Graduação em Administração, Universidade Municipal de São Caetano do Sul, São Caetano do Sul / São Paulo, Brasil.

II Faculdade de Economia, Administração e Contabilidade, Universidade de São Paulo, São Paulo / São Paulo, Brasil. 